\title{
Treatment of papermaking water by using reed constructed wetlands
}

\author{
Changhai $\mathrm{Li}^{\mathrm{a}}$, Yuejin $\mathrm{Li}^{\mathrm{b}}$
}

1Engineering Research Center for Industrial Waste Water Reclamation of Shandong Province, Binzhou 256603, PR China;

alichanghai2000@163.com, bliyuejin83@163.com

Keyword: constructed wetlands;reed; papermaking wastewater; removal efficiency

Abstract: Pilot-scale constructed wetlands planted the reed was constructed to treat papermaking water. The treatment performances of the three wetlands with different operation model for COD, ammonia nitrogen, total phosphorous, BOD5 were investigated. The results show that the removal efficiency of all kinds of pollution indicators for the sequencing batch wetland of alternating dry and wet is better than that of the continuous wetland, and the performance of systems achieved the best in September and October and declined from November. When effective area of wetlands was $30 \mathrm{hm} 3$, irrigation water depth $8 \mathrm{~cm}$, pollutants surface loading $2 \mathrm{~cm} / \mathrm{d}$, and continuous $8 \mathrm{~d}$ and intermittent $2 \mathrm{~d}$ at every year in September, the removal efficiency of COD, ammonia nitrogen, total phosphorous and BOD5 was reached to $34 \%, 28 \%, 25 \%$ and $46 \%$, respectively. The quality of the outlet water met the requirement of recycle water and discharge standard.

\section{Introduction}

Papermakingwastewater has specialities of high concentration of contaminations, complex components and large wastewater quantity ${ }^{[1]}$. Resource comprehensive utilization of papermaking wastewaterhas been a hot area of research ${ }^{[2-4]}$. The settlement-biochemical method is a primary method in wastewater purification at home and abroad, but the papermaking wastewater after treatment method of effluent cannot meet the requirement of discharge standard of "the national standard of water pollutant discharge for pulp and paper industry"(GB3544-2008) ${ }^{[5]} \cdot$ Unless further deep processing technology is used to solve the above problems, but this will increase the cost of processing. Compared with conventional treatment system, the technology of constructed wetland which is viewed as"natural purifier" is easily operated, simple process, low treatment cost, good stability and good ecological effect ${ }^{[6-9]}$. Reed wetland, which is powerful stain resistance, salt-tolerance and evaporation capacity, has been widely used in wastewater treatment. The inland saline areas in the Yellow River delta have larger area of inland saline reed wetlands, which provides an opportunity for reed wetland to treat papermaking wastewater.Reed wetland treatment of papermaking wastewaternot only can make the papermaking wastewater met discharge standard, and can realize the recycle economic pattern of "papermaking wastewater-reed- paper ".Using papermaking wastewater processing SBR as treatment object, and using three pieces of a total of $100 \mathrm{hm}^{2}$ reed wetland to carry out experimental study, the removal effects on COD, ammonia nitrogen, total phosphorusand $\mathrm{BOD}_{5}$ were investigated. The research offers a foundation for the popularization and application of reed wetland in papermaking wastewater treatment technology.

\section{Experiment}

\subsection{The experimental site}

The experimental site was selected in the eastern native reed land covering an area of 100 $\mathrm{hm}^{2}$ near the Tuhai River in the Yellow River delta, Soil in the area belong to the coastal tide soil, and configuration has more thick sticky layer, its distribution is in the altitude from $5 \mathrm{~m}$ along the Tuhai River and the east of Qin mouth river Midstream.The region belongs to the East Asia sub-humid warm temperate continental monsoon climate, the average annual temperatureis $12.5^{\circ} \mathrm{C}$, average precipitation is $600 \mathrm{~mm}$ annually, and the yearly evaporation quantitatively is $1800-2000$ $\mathrm{mm}$. The mass fraction of soil soluble-salt is from $0.4 \%$ to $2.5 \%$, the $\mathrm{pH}$ decreased from 7.8 to 8.9 gradually. 


\subsubsection{The wetland graphic design}

We choose the native reed plots which growth uniform to carry out the research. In order to reduce the cost,the system was consisted of three-stage batch surface flow constructed wetlands. The design surface of experimental plots should look something like Fig. 1.

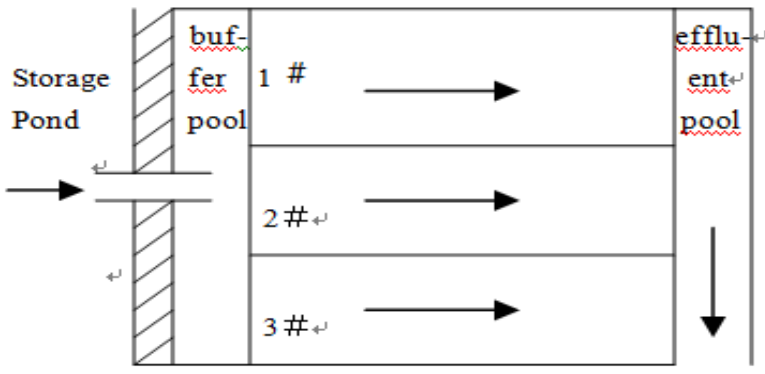

Fig.1 Schematic diagram of the reed wetlands

\subsubsection{The irrigation design of wetland}

The influentwaterof Reed wetlandwas papermaking wastewaterafter SBR treatment which stored in the pond. For the realization of the wastewater circulatory flow in the wetland, and make full useof wastewater treatmentfunctionof wet land, we designed to the frame and water distribution system of wetland, and controlwastewater level and fill order of wetlands. The irrigation technology conditions were shown in Tab.1. First,experiment of wetland treatment of papermaking wastewater was started at low concentration andstartup time was $30 \mathrm{~d}$.For increase the biomassandactivity of the microorganisms, wetland was constructedby continuous injection with $2 \mathrm{~cm} / \mathrm{d}$ hydraulic loading rate.Pool1rancontinuouslyunder the same irrigation depth and surface hydraulic loading rate. Pool2 was implementedby dry-wet rotation and intermittent duty, continuous running $8 \mathrm{~d}$, intermittent $2 \mathrm{~d}$. Pool 3 was implemented by dry-wet rotation and intermittent duty, continuous running $8 \mathrm{~d}$, intermittent $2 \mathrm{~d}$, running time was from August to November.

Tab.1Technical design of reed wetland for papermaking wastewatertreatment

\begin{tabular}{cccccc}
\hline Wet land & Effective area $\left(\mathrm{hm}^{2}\right)$ & Irrigation depth $(\mathrm{cm})$ & Hydraulic load $(\mathrm{cm} / \mathrm{d})$ & runtime $($ month $)$ & Operation description \\
\hline 1 & 40 & 8 & 2 & 4 & the same depth andload \\
2 & 30 & 8 & 2 & 4 & $8 \mathrm{~d}+2 \mathrm{~d}$ \\
3 & 30 & 8 & 2 & 4 & $6 \mathrm{~d}+4 \mathrm{~d}$ \\
\hline
\end{tabular}

\subsection{Materials}

All reagent used were of AR grade. The used papermaking wastewater which by intensified micro-electrolysis-hydrolysisacidification-SBRtechnology was from a local papermaking plant in Shandong.The COD of water averaged $85 \mathrm{mg} / \mathrm{L}$, the mass concentration of ammonia nitrogen was $1.42 \mathrm{mg} / \mathrm{L}$, the mass concentration of total phosphorus average $0.1 \mathrm{mg} / \mathrm{L}, \mathrm{BOD}_{5}$ averaged 30 $\mathrm{mg} / \mathrm{L}$.

1.3Analytical methods

The article utilized the potassium dichromate method (GB/T11914-1989) to measure COD in the experimental conditions. The measure method of $\mathrm{BOD}_{5}$ isthedilutionandseedingmethod dilution (HJ505-2009). Ammonia nitrogen,Nessler's reagent Spectrophotometry was adapted to theammonia nitrogen determinationofwatersamples(HJ535-2009). AMo-Sb spectrophotometric method (GB/T11893-1989)has been applied to determining total phosphorus in water.

\section{Results and discussion}

2.1 The removal of COD in waste water by Reed wetland

When the reed wetlandoperatedstably after the operation,it continuously ran for 7 days. Meanwhile, weanalyzed thechange ofCODinwastewater taken from the channels of different pools every day.The result is shown in Fig. 2.

The result shows that thereed wetland can decontaminate certain pollutantsin the papermakingwastewater, and COD removal rates of the wastewater after treated in the pools of 1,2 , 3 were $28 \%, 34 \%$ and $34.5 \%$, respectively. The approaches for removal of COD were the absorption bythe reedwetland, and the degradation by the rhizosphere microorganism ${ }^{[10,11]}$. 


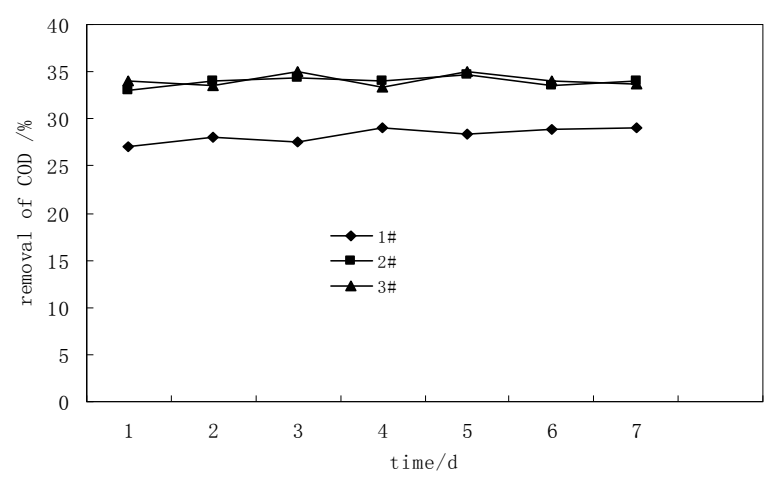

Fig.2 Effect of reed wetlands on removal efficiency of COD

The result shows that No. 2 and No. 3 of pools using dry-wet rotationand intermittent operation in the way of the combination had a higher removal rate of COD than continuous-time-rated pool (No. 1).The reason is that using dry-wet rotation and intermittent operation in the way of the combination can greatly increasethe oxygen supply in the soil, improve the quantity and activity of soil microbe, and promote the decomposition of organic pollutants. Meanwhile, it can avoidtheemergenceofplantrootrot.With continuous running, thewetland was continuous exposed in polluted water over time, the adsorption of the soil reach saturation, so reduce the ability to degrade many kinds of contaminant ${ }^{[12,13]}$.

2.2 The removalof ammonia nitrogenin wastewater byReed wetland

When the reed wetland operated stably after the operation,it continuously ran for 7 days. Meanwhile, we analyzed the change of ammonia nitrogen in wastewater taken from the channels of different pools every day.The result is shown in Fig.3.

The Fig. 3 shows that the reed wetland could certainly remove ammonia nitrogen from the wastewater like COD.The removal rateof ammonia nitrogen inNo. 2 and No. 3 of dry-wet alternation pools come up to $28 \%$ and $29 \%$ respectively. The ammonia nitrogen was removed mainly by adsorption, nitrification/denitrification and plant/microorganism absorbtion. The degradation of ammonia nitrogen in the wastewater also mainly relied on reed wetland plants and microorganisms, but the biodegradation of ammonia nitrogen is more complicated.Because of the intermittent operation mode existedthe alternationof aerobic-anoxic environments, more nitrogen was decomposed by stronger microbial activity. So the removal rateof nitrogen ofNo. 2 and No. 3 pools is higher than that of the No. 1 pool.

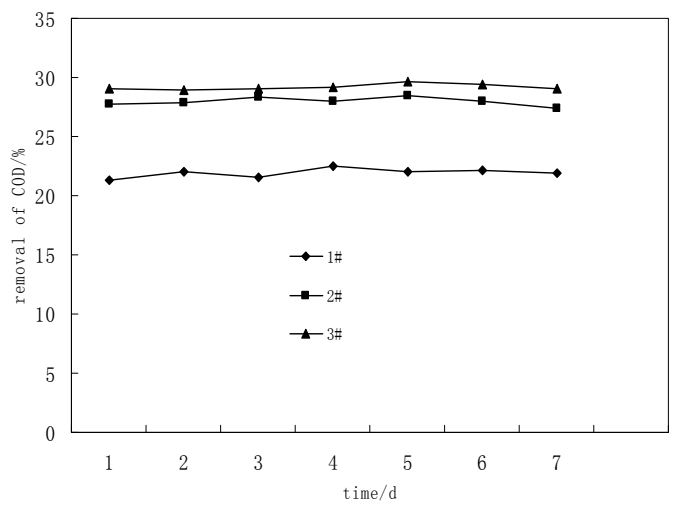

Fig3. Effect of reed wetlands on removal efficiency of ammonia nitrogen

2.3The removal oftotal phosphorusin wastewater by Reed wetland

As mentioned above conditions, the change of total phosphorus in wastewater as shown in Fig. 4. 


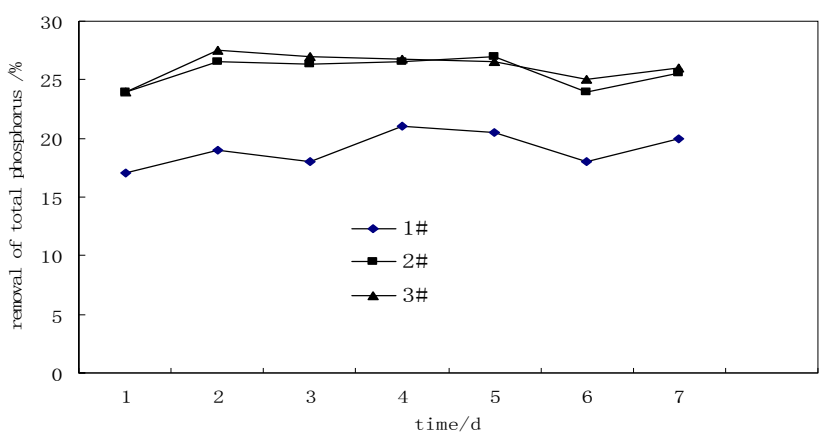

Fig.4 Effect of reed wetlands on removal efficiency of TP

As showed in Fig. 4 the total phosphorus removal rate of No. 1 poolcontinuously operating was $19 \%$, the removal rate of total phosphorus by No. 2 and No. 3 pools treatment come up to $25 \%$ and $27 \%$ respectively. The total phosphoruswas removed mainly byreed wetland adsorptionplant /microorganism absorbtion. There are evidence shows thatabout $28 \%-59 \%$ oforganic matter forming the plant photosynthesisis transferred to the underground, $4 \%-70 \%$ of the organic matter through root secretion into the soil. The roots secretion created a good condition for the survival of microorganisms, and promoted the rhizosphere biodegradation ${ }^{[14,15]}$. Research shows reed wetland dry-wet alternation process makes the soil in the alternating phase of aerobic-anoxic-anaerobic, which is of benefit to phosphate removaland increase the phosphate sorption capacity of the soils ${ }^{[16,17]}$.

2.4The removal of $\mathrm{BOD}_{5}$ in wastewater by Reed wetland

The Fig. 5 shows that theaverage $\mathrm{BOD}_{5}$ removal efficiency of No. 1 poolcontinuously operating was $32 \%$. The removal rateof $\mathrm{BOD}_{5}$ by No. 2 and No. 3 pools treatment come up to $46 \%$ and $50 \%$. The $\mathrm{BOD}_{5}$ was removed mainly by biodegradation in wetlands, sediment, and plant/microorganism absorbtion, and one of the most important influence factorsis aerobic effect.Dry-wet alternation process of No. 2 and No. 3 pools makeshigh aerobic capacity, so the removal rateof $\mathrm{BOD}_{5}$ is higher than that of the No. 1 pool which has poor oxygen condition and less oxygen.

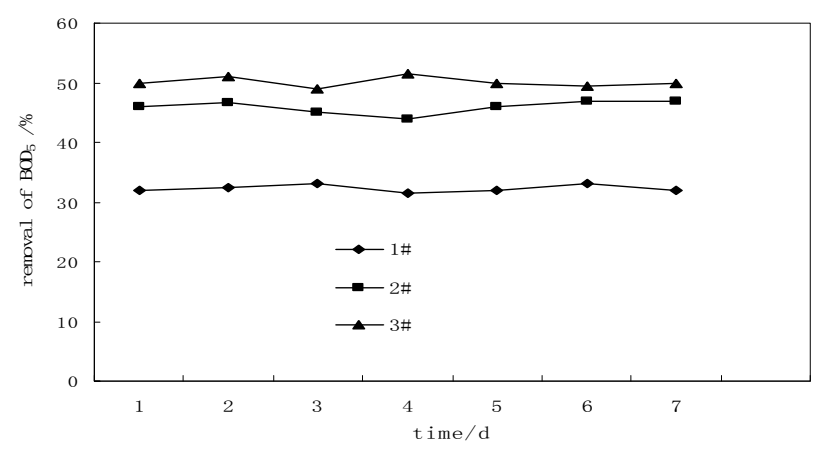

Fig. 5 Effect of reed wetlands on removal efficiency of $\mathrm{BOD}_{5}$

\subsection{The running status of reed wetland in summer and fall seasons}

Wetland ecosystem run under the following conditions, the depth of irrigation was 8 $\mathrm{cm}$,surface hydraulic loadingwas $2 \mathrm{~cm} / \mathrm{d}$, and four months of continuous operation fromAugust to November in 2014, in other words, it experienced summer, autumn and winter. The result of the CODremove rate was shown in Fig. 6.The removal of COD of three wetlands increased at first and then decreased in the process of from summer to early winter, and remove rateis higher in Sep, and later peaked in Oct. Results by comparison showed that the removal rate of pool 1 was minimum, the removal rate may not vary much between pool 2 andpool 3, and pool 3 removal rate slightly higher than thatof pool 2. From August to October, the average temperature increased from $28^{\circ} \mathrm{C}$ to $35^{\circ} \mathrm{C}$. The activity of microorganisms degradation of pollutants and COD removal rate were increased.At the same time, the rise of temperature is beneficial to the reed growth, so the fixed action by plant tissuethrough adsorption was strengthen. In addition, the microbial film system can help speed the degradation rate of pollutants further ${ }^{[17]}$. The microbial activity and degradation rate of wetland system werereducedfor temperature dropping in winter. Reed plant also gradually 
decline, and their fixation was decreasing. At the same time, there was a decrease in oxygen supply of wetland system ${ }^{[18]}$, leading to lack enough dissolved oxygen for the aerobic microorganisms in pollutants, and COD removal rate decreased obviously.

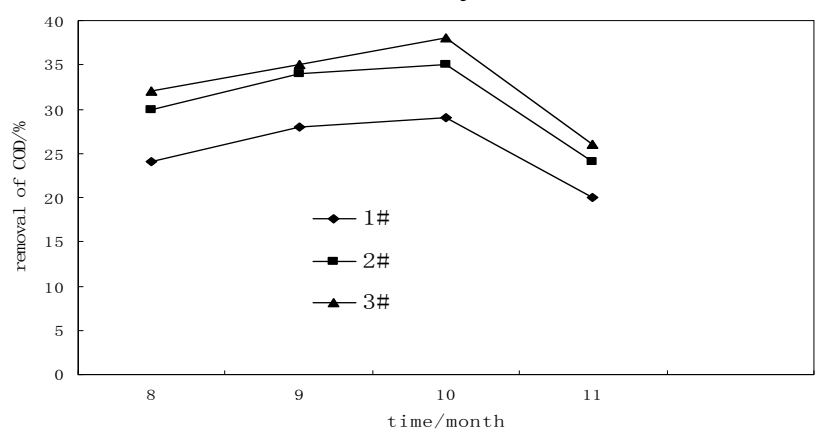

Fig.6 Removal efficiency of COD during operating period

2.6 The quality analysis of papermaking wastewater purified by reed wetland

The experimental results of $\mathrm{COD}, \mathrm{BOD}_{5}$, ammonia nitrogen and phosphorus by three pieces of wetland in three operationmodes showed that No. 2 and No.3.The removal rate of pollution indicators such as COD in intermittent operation wetlands 2, 3were higher than that of continuous operation wetland 1.Meanwhile, the removal rate of each index of No.3 wetland was slightly higher than that of No. 2 wetland, but the wastewater treatment capacity of No.3 wetland was lower than wetland2. Pollutant removal and the wastewater treatment capacity requirements were analyzed and considered, the design parameters and operation mode of No. 2 wetland treated with papermaking waste water were adoptedin experiments.Under the optimum conditions, the average removal rate of COD, ammonia nitrogen, total phosphorus and $\mathrm{BOD}_{5}$ were $34 \%, 28 \%, 25 \%$ and $46 \%$, respectively. The characteristics of influent and effluent wastewaterwere shown in Tab. 2

Tab. 2 The characteristics of influent and effluent wastewater

\begin{tabular}{cccll}
\hline Water sample & $\mathrm{COD} /\left(\mathrm{mg} \cdot \mathrm{L}^{-1}\right)$ & $\mathrm{NH}_{4}{ }^{+}-\mathrm{N} /\left(\mathrm{mg} \cdot \mathrm{L}^{-1}\right)$ & $\mathrm{TP} /\left(\mathrm{mg} \cdot \mathrm{L}^{-1}\right)$ & $\mathrm{BOD}_{5} /\left(\mathrm{mg} \cdot \mathrm{L}^{-1}\right)$ \\
\hline IN & 85.00 & 1.42 & 0.10 & 30.00 \\
OUT & 56.00 & 1.02 & 0.08 & 16.00 \\
\hline
\end{tabular}

\section{Conclusions}

The following conclusions can be drawn from the present work:

(1)Wetlands planted the reed were constructed to treat papermaking wastewater. At every year in September, When effective area of wetlands, irrigation water depth and pollutants surface loadingwere $30 \mathrm{hm}^{3}, 8 \mathrm{~cm}$, and $2 \mathrm{~cm} / \mathrm{d}$ respectively, and the time of continuous running andshutdown were $8 \mathrm{~d}$ and $2 \mathrm{~d}$, the removal efficiencies of COD, ammonia nitrogen, total phosphorous and $\mathrm{BOD}_{5}$ under principles under those particular conditions were reached to $34 \%, 28 \%, 25 \%$, and $46 \%$, respectively. The treated papermaking water met the requirement of recycle water and discharge standard.

(2) Experiment adopted continuous and intermittent operation types. For dry-wet intermittent operation of No. 2 and No. 3 pools, theirs indicators of sewage treatment such as COD removal rate were much higher than that of continuous operation pool (No.1). The removal rate of pool 3 which has long water supply cut-off time was slightly higher than pool 2 . The design parameters and operation mode of No. 2 wetlandtreated with papermaking wastewater ware formulated through experiments.

(3)Adopting the combination offlooding-drying alternationand intermittent working fashioncan significantly improve the oxygen supplyinthe soil, provide oxygen and substrate conditions, increase amount and microbial activity of aerobic microorganisms. So the decomposition of organic pollutants in soil was promoted.

\section{Acknowledgements}

This work was financially supported by the Science and Technology Development Plan Project of 
Shandong Province China (No. 2011GSF11713) the Science Technology Development Program of Binzhou, China (GrantNo. 2014ZC0312).

\section{References}

[1] D.B. Zarkovic, Z.N. Todorovic, L.V. Rajakovic. Simple and cost-effective measures for the improvement of paper mill effluent treatment: A case study [J]. Journal of Cleaner Production, 2011, 19(6-7): 764-774.

[2] M.C. Monte, E. Fuente, A. Blanco, et al. Waste management from pulp and paper production in the European Union[J]. Waste Management, 2009, 29(1): 293-308.

[3] S.Y. Lv, C.R. Zhang, L.L. Tang, et al. Advanced treatment of paper-making wastewater byFe ${ }_{2} \mathrm{O}_{3} / \gamma-\mathrm{Al}_{2} \mathrm{O}_{3}$ catalytic oxidation[J]. Industrial Water Treatment, 2014, 34(7):42-45.

[4] Khan S, Asghar M N , Rana T. Tariq characterizing groundwater dynamics based on impact of pulp and paper mill effluent irrigation and climate variability[J]. Water Air Soil Pollute, 2007, 185(1-4):131-148.

[5] Z.P. Li, Q.J. Liu, Q.T. Lin, et al.TheApplicationStudyProgressofAdvanced Treatment Technologyof Paper makingWastewater [J]. Transactions of China Pulp and Paper, 2010, 25 (1): 102-107.

[6] Li Xianfa, Jiang Chuncai. Constructed wetland systems for water pollution control in North China[J]. Water Science and Technology, 1995, 32( 3) : 349- 356.

[7] J.B. Xia, Q. Liu, W.J. Xie, et al. Effect of wastewater irrigation on soil hydrological properties in reed marsh [J]. Transactions of the Chinese Society of Agricultural Engineering, 2009, 25(12): 63-68.

[8] Y.H. Chen, X.F. Wu, J. Hao, et al. The adaptability and decontamination effect of four kinds of woody plants inconstructed wetland environment [J]. Acta Ecologica Sinica, 2014, 34(4): 916-924.

[9] D. Huang, W. Xiong, K. Liu, et al. Temporal-spatial variations of water quality in a reclaimed-water-suppliedconstructed wetland purification system: A case study in Olympic Forest Parkof Beijing [J]. Acta Scientiae Circumstantiae, 2014, 34(7): 1738-1750.

[10] Q.Y. Zhou, S.F. Wang. Microbiology of Environmental Engineering[M].Beijing: Higher Education Press, 2007:146-163.

[11] G.K. Fu, M. Wang, Z. Zhang, et al. Reaction Kinetics of Three Types of Constructed Wetland for Advanced Domestic Wastewater Treat [J]. Journal of Civil,Architectural \& Environmental Engineering,2012, 24(4):111-117.

[12] H.Z. Li, J.F. Ye, Z.X. Xu.Influenceofalternateoperationonclogginginavertical-flow constructedwetland [J]. ActaScientiaeCircumstantiae,2008,28(8):1555-1560.

[13] J.S. Guo, C.Y. Wang, F. Fang, et al. Influence ofWet /Dry Ratio on PollutantsRemoval Performance byRapid Infiltration System [J]. China Water \& Wastewater,2006,22(17):9-12.

[14] Butler J L, Williams M A. Microbial community dynamics associated with rhizosphere caron flow[J]. Applied and Environmental Microbiology, 2003, 69(11):6793-6800.

[15] S.L. Zhang, L.W. Fan, N.Q. Chen, et al.Purification of papermaking tail-water by constructed wetlandsand the screening of dominant wetland plants[J].Chinese Journal of Environmental Engineering, 2014,8(9): 3718-3723.

[16] S.Y. Lu, P.Y. Zhang, G. Yu, et al.Wet - dry Seasonal Regularity of Phosphorus Removal from Agricultural Runoff by Constructed Wetland in Wang jiazhuang Lakeside Area [J]. Journal of Agro-Environment Science,2006,25(5):1313-1317.

[17] Ghadiri H. Degradation of endosulfan in a clay soil from cotton farms of western Queensland [J]. Journal of Environmental Management, 2001, 62(2):155-169.

[18] S.P. Zhang, W.J. Zhang, Y.L. Li, et al. TheAnalysis of Bioactivity and Environmental Effect of Different Types of Wetland Soil in ChongmingDongtan [J]. Journal of Agro-Environment Science, 2009, 28(1): 112-118. 